\title{
Participatory IT for In-situ and Ex-situ Collaborative Writing in Semi-public Spaces
}

\author{
Anna Maria Al Zubaidi-Polli \\ Johannes Kepler University Linz \\ Altenbergerstrasse 69, 4040 Linz, Austria \\ Anna.Polli@fh-hagenberg.at
}

\author{
Gabriele Anderst-Kotsis \\ Johannes Kepler University Linz \\ Altenbergerstrasse 68, 4040 Linz, Austria \\ Gabriele.Kotsis@jku.at
}

\begin{abstract}
This paper reports on two design experiments aiming to support participation in the semi-public space of an art gallery. Through 36 interviews, we analysed the collaborative production of texts about artworks both in the physical space of the art gallery and in the digital realm. In the first experiment, the prototype explicitly enabled in-situ collaborative writing, while in the second experiment the prototype enabled both in-situ and ex-situ collaborative writing. Our findings help us to better understand and further enhance the notion of participatory IT based on actual use. We analysed in-situ and ex-situ collaborative writing activities using the two prototypes, which led us to propose four new strong concepts for supporting the understanding and design of participatory IT that fosters local and remote participation linked to a semi-public space.
\end{abstract}

\section{Strong concepts, Participatory IT, Support Participation, In-Situ and Ex-situ collaborative writing.}

\section{INTRODUCTION}

Research has been interested in supporting in-situ participation and on mechanisms that foster debate, deliberative decision-making (Cindio and Schuler, 2012), or collaborative knowledge production (Polli et al., 2013; Bødker et al., 2014). We are interested in how these mechanisms can be linked to a specific locality or a semi-public space. We focus on mechanisms and concepts that support both in-situ and ex-situ participation. We borrow the terms in situ and ex situ from Bohøj et al. (2011), where in-situ and ex-situ engagement in public refer, respectively, to citizens' activities relating to an object under discussion a) at the physical location and b) remote from the location. Extending participation from in-situ to ex-situ may engage participants in writing one coherent collaborative text about an object. Hence, we are exploring the notion of participatory information technology (PIT) that is local and at the same time global. The PIT is physically embedded in a shared, semi-public place and accessible in-situ via mobile phones and ex-situ via an e-deliberation platform. Using an e-deliberation platform supports the users in collaborative discussions and in writing one collaborative text containing the consensus of the participants (Al Zubaidi-Polli et al., 2017).

With the term PIT, we refer to an information technology that inherently involves a shift of power from an institution, such as an art gallery, to the public (Bødker et al., 2014). An activity that is normally in the hands of a curator becomes participatory, involving citizens who have an interest in interpreting art. The interconnection of local and global PIT is explored through two design experiments: we describe the actual use of two prototypes via a) mobile devices as interfaces to a shared physical space and b) an e-deliberation platform as a means of connection to the physical space from a remote location. Thus, we seek to engage citizens in art galleries by allowing them to participate in continuous collaborative activities both in-situ and ex-situ. Giving citizens continuous access to a means of contributing - as with Wikipedia, where people can contribute irrespective of their location - facilitates production of a collaborative text (Bryant et al., 2005). We investigated this approach using our prototypes placed in a semi-public space - an art gallery.

\section{RELATED WORK}

While traditional museums use official interpretations written by the curators, it is becoming more common for contemporary institutions to support visitors in engaging with artworks and determining their own way of making meaning (Whitehead, 2011). Research studies are focusing on engaging visitors when they are in-situ at the museum, but do not look into the advantages of inviting participation remote from the museum (Fosh et al., 2014; Ferris et al., 2004; Macdonald, 2007). Chalmers and Galani highlighted the lack of research that bridges between local and remote 
technologies in museums (Fosh, 2015). In (Bødker et al., 2014), the first seminal experiment involving Participatory IT that is local to an art gallery and physically embedded in this shared and public setting was described ${ }^{1}$. However, the authors investigated only in-situ collaborative writing. They presented three strong concepts ${ }^{2}$ that, when used in designing new PIT, put an emphasis on in-situ engagement only. To support the engagement of a coherent collaborative art interpretation production, the extension from in-situ to ex-situ participation is recommended (Al Zubaidi-Polli and Verdezoto, 2018).

\section{BACKGROUND}

The research presented in this paper builds upon the analysis of two design experiments: our initial design experiment, Local Area Artwork (LAA) (Polli et al., 2013; Bødker et al., 2014) and the follow-up design experiment, Aarhus's Artwork (AA) (Al Zubaidi-Polli et al., 2017). Our initial research project, LAA, focused on in-situ collaborative art interpretation writing (Bødker et al., 2014), and the follow-up study, AA, explored the extension to exsitu interpretation writing (Al Zubaidi-Polli, 2017).

In our LAA design experiment, we placed a collocated collaborative writing system into an art gallery to encourage local art discussions, and thus provided a platform for the public to actively participate in composing interpretations of individual artworks. We replaced the curatorial texts next to the artworks with mini iPads and invited people to participate and write their own interpretations (Polli et al., 2013; Bødker et al., 2014).

In the follow-up design experiment (AA), we introduced an e-deliberation platform that enabled visitors to write a coherent art interpretation not only in situ, but also ex situ in a relaxed atmosphere to reflect on the artwork. As in the first study, the traditional interpretation panel was replaced, but this time with our e-deliberation platform. Our platform, provided an online space for participation where visitors could meet to discuss and write a collaborative interpretation of a chosen artwork (Al Zubaidi-Polli and Verdezoto, 2018).

Using this platform, we sought to investigate how an e-deliberation platform can engage citizens in writing a coherent collaborative text (Al ZubaidiPolli et al., 2017). At the end of the study, we reached a contextual consensus of the different interpretations submitted by the citizens, which

\footnotetext{
${ }^{1}$ This design exemplar is our initial design experiment Local Area Artwork mentioned in this paper (see Section 3).

2 Hoök and Löwgren (2012) describe strong concepts as an intermediate-level knowledge form that can emerge from designoriented $\mathrm{HCl}$ research: "Strong concepts are design elements abstracted beyond particular instances, which have the potential to be appropriated by designers and researchers."
}

resulted in one final collaborative written interpretation.

Through these two studies we gained a better understanding of in-situ and ex-situ participation and the notion of PIT. We were able to identify a) challenges that counteract coherent collaborative production of text $b$ ) tensions relating to in- and exsitu engagement and c) appropriation practices of the technologies deployed in the design experiments. This analysis forms a fundamental basis for the strong design concepts we present in this paper to understand the notion of PIT supporting in-situ and ex-situ collaborative writing.

\section{RESEARCH METHODOLOGY}

The setup in the LAA experiment was limited to one month, which was the duration of the exhibition in the gallery. We thus carried out an in-the-wild study (Brown et al., 2011). We conducted 13 semistructured on-site interviews with 19 visitors (some in pairs). The follow-up design experiment lasted three months. 23 participants, who had an interest in art curation, were invited to use our edeliberation platform. We conducted 23 semistructured interviews. All interviews from both cases were transcribed and then analysed using inductive coding. The initial codes were related to our design ideas, such as collaborative writing, coherent text production, appropriation practices, mobile/e-platform and artwork. What caught our attention when analysing and comparing the interviews were the contradictions, how people talked about writing when being close to or remote from the artwork, how they tackled difficult questions, etc. Accordingly, we took a closer look at the conflicts.

\section{FINDINGS AND ANALYSIS}

\subsection{Short messages vs. coherent text}

In the LAA set-up, we experienced that people were writing short messages rather than a coherent interpretation as we had anticipated. Firstly, this may have resulted from our design decision of 'local-write and global-read' (Bødker et al., 2014), which means that visitors were allowed to edit the text next to the artworks only when being within a distance of 3 meters. When they were outside the gallery, they had read-access only. Secondly, we found that for writing a coherent art interpretation, visitors prefer to be in a relaxed atmosphere (Al Zubaidi et al., 2017). The visitors mentioned they need more time to reflect upon the artwork to write an elaborate text. Thirdly, the technology on site gave rise to conversations and discussions among visitors. Hence, at times the system served as a conversation starter rather than as a collaborative writing tool. Fourthly, we followed an open-design principle, which means that we gave access to a 
format of contributions that was open to being shaped by the audience without previous introduction. The collaborative writing technology offered a blank sheet on which anything could be written. This approach created a number of challenges, for example, that this openness led to contradictory uses. We identified various attempts to share individual thoughts about the artwork that conflicted with each other, so no coherent text could emerge. Rather than write one coherent interpretation, the visitors added comments that resembled guestbook or Facebook entries (Bødker and Polli, 2014).

\subsection{In-situ vs. ex-situ writing}

In the AA study, when writing informative, coherent interpretations, the participants acted collaboratively, as they adapted other interpretations or incorporated others' ideas into their own texts. The writing practices related to composing a coherent text constitute one group of findings within our analysis. We identified ex-situ situations in which visitors felt sufficiently comfortable to write Wikipedia-style art interpretations. The participants domesticated the technology in various places inside and outside their homes: on the couch, in bed, at the dining table or at the desk, at the office, and while commuting on public transport.

Further analysis from the LAA study revealed contradictions regarding the preferred ex-situ situations in which to write the collaborative interpretation: One interviewee mentioned that, she probably would have forgotten on her way home to write an interpretation. Therefore, she would have preferred a 'cozy place' in-situ at the art gallery, such as in a café lounge, to reflect on and write her interpretation. Even though most of the interpretations were written in ex-situ situations, this finding indicates the need for a PIT allowing insitu and ex-situ writing to cater to individual preferences.

\subsection{Digital vs. face-to-face dialogues}

A further limitation we identified in the AA design experiment concerns the absence of human assistance. Users need the reassuring feeling that there is help when they require it and the opportunity to ask questions and discuss difficulties, preferably face-to-face. The participants became increasingly frustrated with some unfamiliar and non-intuitive functionalities of our edeliberation platform. Interventions by other participants prevented them from discarding the platform. The participants met on a weekly basis due to their academic background and used these meetings to discuss the open questions. When users do not have the required knowledge to participate constructively in the collaborative activities and no human assistance is provided, this frustration may lead to rejection of a platform.

Some of our participants highlighted that they would have preferred closer contact to us researchers and developers of the platform. Although the platform offered a discussion forum, it was rarely used to get in contact with us researchers. The participants had several questions and faced difficulties regarding the platform; nonetheless, the discussion forum remained largely unused. Direct face-to-face contact was preferred to the online discussion forum of the e-deliberation platform.

\section{STRONG CONCEPTS FOR PIT}

In this section, we present six strong concepts that are based on our analysis. First, we present two strong concepts which are derived from our first design exemplar of PIT (Bødker et al., 2014), which is followed by four new strong concepts (see Sections 6.1 to 6.4). These concepts are intended to support the understanding and the design of participatory IT that fosters local and remote participation linked to a semi-public space.

In (Bødker et al., 2014), we presented three strong concepts: Local Area networking, hyperlocality and global read/local write. The first two can be adopted, as they support but do not limit to in-situ engagement. Using local area networking as a design concept means creating a digital layer that is tied to the physical space via fixed and/or mobile devices present in the space. With the concept hyperlocality we steer attention towards designing for participation and collaboration that centres on shared, collocated objects, taking into account the immediate physical social environment. Applying these two concepts supports in-situ participation with the possibility for further extension to remote participation. The third concept global read/local write limits participation explicitly to in-situ engagement. We modified this concept to obtain a new strong concept (see Section 6.1). In addition, the AA experiment allowed us to derive three new concepts that directly support ex-situ collaboration (Sections 6.2-6.3).

\subsection{Location-agnostic collaborative writing}

This concept relates to the successful writing of constructive coherent collaborative texts in the AA experiment. We experienced a sustained participation that compares to that Wikipedia affords. People cared much more about their contributions and how they were received and adopted by others. They gained strong ownership of the collaboratively produced text, and therefore they followed up on the collaborative text production and actively participated in the writing process. This concept provides access to those 
present in the space (in situ), to those who read about any changes in the collaboratively written text (ex situ), and to those who actively want to participate in further text production about an artwork located in a semi-public space (both in situ and ex situ). Allowing remote participants to follow up on the collaborative text production and to allow them to write more text, and delete or edit it better sustains participation than limiting access to in-situ participation. With this concept, the power dynamics are balanced between the local and the global level and the people present in the physical space. In summary, using location-agnostic collaborative writing as a design concept means extending access beyond the local reach and removing the restraint of physical presence next to the object under discussion.

\subsection{Brainstorm-integrate-merge cycle}

This concept relates to three relevant activities that had an impact on achieving a consistent written text. In the LAA set-up, the use of personal devices led to individual participation and to writing short snippets of text rather than writing a coherent interpretation. In the AA set-up, we supported engagement to achieve composition of a coherent interpretation through three activities. Initially, the participants brainstormed individually or in groups about possible interpretations. Each of them then drafted one interpretation for the artwork and submitted it to the e-deliberation platform. Subsequently, they read each other's interpretations, which inspired them to write new interpretations, to integrate ideas or copy lines of text into their own. This cycle of brainstorming, writing and re-writing was repeated four times, thus merging the interpretations into one final coherent interpretation. In summary, using brainstormintegrate-merge as a design concept means steering participants' collaborative writing towards achieving a coherent collaboratively written text.

\subsection{Contextual consensus}

This concept relates to finding one contextual consensus within various submitted art interpretation proposals. In our ex-situ set-up, we experienced that our e-deliberation algorithm supported the evolvement of one final interpretation containing the contextual consensus of 58 submitted interpretations. The core feature of this concept is called the human-based genetic algorithm (HBGA) (Di Fenizio and Anderson, 2011). Using this algorithm supports the deliberation- and the decision-making processes for finding common ground in the different proposals. Our participants ranked each submitted interpretation, assigning 0-3 stars. The algorithm then calculated the fitness for each interpretation, whether it had high or low fitness. After evaluation of the fitness, an interpretation was marked as discarded or as highlighted. Based on these results, the participants were invited to write a new interpretation that integrated ideas from highlighted interpretations. The HBGA allows citizens to find common ground and a shared solution, proposal or a collaboratively written text as the result of a collaborative process (Al Zubaidi-Polli et al., 2017). In summary, using the contextual consensus as a design concept means inviting constructive, moderated participation that is supported by a human-based genetic algorithm.

\subsection{On- \& offline discussions}

With the concept of on- \& offline discussions, we support collaboration and conversation at two levels: a) direct, real-time, and face-to-face with those collocated in the physical space (acquaintances or strangers) and b) over the course of the exhibition with other visitors remote from the physical space, using the discussion forum in the digital realm. Our analyses from our two studies revealed that it is important that users have a space where they can share their problems regarding the technology and discuss solutions that facilitate interaction. In the AA set-up, establishing face-to-face communication was fairly easy, as the participants met each other on a weekly basis due to their academic backgrounds. This provided them with a space where open questions could be addressed. In the LAA set-up, visitors could approach the gallery staff or ask their acquaintances when questions arose. However, when remote from the gallery, the ability to turn to a more knowledgeable person is essential. If this opportunity is not given, individuals will most likely dis-appropriate the PIT when encountering the first problems. In summary, using on- \& offline discussion as a design concept means enabling participants to continue their conversations and providing guidance regardless of their physical location.

\section{CONCLUSION}

The strong concepts presented in this paper support both in-situ and ex-situ engagement within the specific design case at hand. Our concepts demonstrate both how to encourage people to participate in a physical local place and how to sustain their interest in participation when remote from the local place. Moreover, these strong concepts are steps towards a better understanding of the notion of PIT from actual use, towards designing to support participation and thus towards Participatory IT. They are valuable when designing technologies linked to a particular public place. The concepts support collaborative coherent text production and allow users to gain ownership and a stronger connection to a public place. 


\section{REFERENCES}

Al Zubaidi-Polli, A. M., and Verdezoto, N. (2018) "Learning from Appropriation Practices: Towards the next generation of an e-participation environment enabling collaborative art interpretation writing in-situ and ex-situ," Int. J. Pervasive Comput. Commun., vol. 14, no. 1, pp. 49-72.

Al Zubaidi-Polli, A. M., and Verdezoto, N. (In Prep.) "Collaborative Technology Appropriation: A Case of Groups Using a Deliberative Community Network".

Al Zubaidi-Polli, A. M., Verdezoto, N., Al Zubaidi RSmith, N., and Anderst-Kotsis, G (2017) Ex-situ Technology Appropriation of an e-Deliberation platform in an Art Gallery, in Proceedings of the 19th International Conference on Information Integration and Web-based Applications \& Services (iiWAS2017), Salzburg, Austria.

Black, Graham (2012) Transforming Museums in the Twenty-First Century, in Routledge: London, UK, New York, NY, USA.

Bohøj, M., Borchorst, N. G., Bødker, S., Korn, M., and P.-O. Zander. (2011) Public deliberation in municipal planning: supporting action and reflection with mobile technology, in Proceedings of the 5th International Conference on Communities and Technologies, New York, NY, USA, pp. 88-97.

Bødker, S., Klokmose, C. N., Korn, M., and Polli, A. M. (2014) Participatory IT in Semi-public Spaces," in Proceedings of the 8th Nordic Conference on Human-Computer Interaction: Fun, Fast, Foundational, New York, NY, USA, pp. 765-774.

Bødker, S and Polli, A. M. (2014) Between initial familiarity and future use: A case of collocated collaborative writing," in COOP 2014Proceedings of the 11th International Conference on the Design of Cooperative Systems, Nice (France), pp. 137-154.

Brown, B., Reeves, S., and Sherwood, S. (2011) Into the wild: challenges and opportunities for field trial methods. In Proceedings of the SIGCHI Conference on Human Factors in Computing Systems (CHI '11). ACM, New York, NY, USA, 1657-1666.

Bryant, S. L., Forte, A., and Bruckman, A. (2005) Becoming Wikipedian: Transformation of Participation in a Collaborative Online Encyclopedia, in Proceedings of the 2005 International ACM SIGGROUP Conference on Supporting Group Work, New York, NY, USA, pp. 1-10.
C. Whitehead, (2011) Interpreting Art in Museums and Galleries. Routledge.

De Cindio, F., and Schuler, D. (2012) Beyond Community Networks: From Local to Global, from Participation to Deliberation. The Journal of Community Informatics, North America.

Di Fenizio, P. S., and Anderson, C. (2011) Using Pareto Front for a Consensus Building, Human Based, Genetic Algorithm, in Proceedings of the 10th European Conference on Advances in Artificial Life: Darwin Meets Von Neumann Volume Part II, Berlin, Heidelberg, pp. 175-182.

Galani, A., and Chalmers, M. (2002) Can You See Me? Exploring Co-Visiting between Physical and Virtual Visitors. Presented at ICHIM 2002, Boston. MA

Höök, K., and Löwgren, J. (2012) Strong concepts: Intermediate-level knowledge in interaction design research. ACM Trans. Comput.-Hum. Interact. 19, 3, Article 23 (October 2012), 18 pages.

K. Ferris, L. Bannon, L. Ciolfi, P. Gallagher, T. Hall, and M. Lennon, (2004) "Shaping Experiences in the Hunt Museum: A Design Case Study," in Proceedings of the 5th Conference on Designing Interactive Systems: Processes, Practices, Methods, and Techniques, New York, NY, USA, pp. 205-214.

L. Fosh, (2015) "Performing Interpretations of Museum Exhibits in Groups," in Proceedings of the 17th International Conference on HumanComputer Interaction with Mobile Devices and Services Adjunct, New York, NY, USA, p. 11421145.

L. Fosh, S. Benford, S. Reeves, and B. Koleva, (2014) "Gifting personal interpretations in galleries," presented at the SIGCHI Conference on Human Factors in Computing Systems, Toronto, Ont., pp. 625-634.

Macdonald, S. (2007) "Interconnecting: museum visiting and exhibition design," CoDesign, vol. 3 , no. sup1, pp. 149-162.

Polli, A. M., Korn, M., and Nylandsted Klokmose, C. (2013) Local Area Artworks: Collaborative Art Interpretation On-site, in Proceedings of the 2013 ACM Conference on Pervasive and Ubiquitous Computing Adjunct Publication, New York, NY, USA, 2013, pp. 79-82.

Thom-Santelli, J., Cosley, D., and Gay, G. (2010) What Do You Know?: Experts, Novices and Territoriality in Collaborative Systems, in Proceedings of the SIGCHI Conference on Human Factors in Computing Systems, New York, NY, USA, 2010, pp. 1685-1694. 